\title{
Aquino, Txai Terri Valle et alli. Papo de Índio. Manaus, UEA Edições, 2012. 351 pp.
}

Edilene Coffaci de Lima

(UFPR)
É muito benvinda a publicação do livro Papo de Índio, do antropólogo Terri Aquino - ou Txai Terri Aquino - pela editora da Universidade Estadual do Amazonas. O título do livro é o mesmo da coluna que, a partir de outubro de 1987, o autor assinou e organizou inicialmente no jornal A Gazeta, em Rio Branco, Acre.

Neste primeiro volume - há outros dois ainda em preparação - estão reunidos 51 Papos, escritos até meados de 1991, de autoria do próprio Terri ou de seus amigos e colaboradores, índios e não índios, e de alguns detratores. Essa é, aliás, uma marca dos Papos: reunir todos que, de uma maneira ou de outra, se dispõem a tratar publicamente dos assuntos indígenas e das populações tradicionais, notadamente dos seringueiros, dado que a paisagem socioambiental onde se passam os assuntos tratados nos Papos é sempre o Acre, mas com interferências de ordem variadas no período dos Papos reunidos neste volume, pelo menos até a promulgação da Constituição de 1988, a interferência maior era do Conselho de Segurança Nacional e sua famigerada proposição de estabelecer Colônias Indígenas (ver principalmente os Papos que se iniciam nas páginas 52 e 78).

A reunião desses Papos em um único volume, que vão de outubro de 1987 a meados de 1991, faz destacar também essa qualidade: tornar ainda mais visível a pluralidade da coluna, a diversidade, seja das temáticas, das abordagens, dos diversos habitantes daquelas terras, com e sobre os quais se fala. Os Papos são como conversas livres, abertas a argumentos e contra-argumentos, que resvalam algumas vezes na exposição de tensões, conflitos e dissonâncias. Ao invés de ser um empecilho, essa pluralidade é o que faz o próprio vigor da coluna que começou semanalmente e depois foi publicada ao sabor da disponibilidade de seu organizador, visto que ele tinha também mais o que fazer - especialmente viajar pelos rios e varadouros do Acre, notadamente na bacia do rio Juruá, em jornadas de campo para fomentar debates, implantar e acompanhar ações que redundaram no Acre contemporâneo, com um Campos 12(2): 129-133, 2011. mosaico de terras indígenas e áreas de conservação ambiental demarcadas, como 
as primeiras Reservas Extrativistas - e não custa lembrar que o Acre, seja ao sul seja ao norte, foi o lugar onde a ideia de reservas extrativistas foi gestada e primeiramente implementada. Entre os amigos e colaboradores nos Papos de Terri estão antropólogos como Mauro Almeida, Alfredo Wagner Berno de Almeida (que assina também o prólogo) e Mary Allegretti, o poeta Antônio Alves e seu colaborador e amigo, Antônio Luiz Batista de Macêdo. Entre os amigos índios estão Carlito Cataiano, Siã kaxinawá e Ailton Krenak, entre outros.

Certamente não há como esmiuçar aqui detalhes de cada um dos Papos que compõe o livro. Alguns, de todo modo, acabam chamando mais a atenção que outros. Assim, logo no segundo Papo, após ter apresentado suas intenções com a coluna na semana anterior, Terri recupera uma antiga entrevista que fez, acompanhado do sertanista José Carlos Meirelles, com Pedro Biló, um afamado "herói cultural dos cariús [brancos]", no começo da década de 1980. Por vezes o entrevistado lembra um personagem de Guimarães Rosa ou a poesia de Manoel de Barros, como ocorre ao comentar sobre seus conhecimentos para deslocar-se pelas densas florestas aos entrevistadores, quando pontuou que "cada água tem seu jeito, tem seu sistema de correr". Ou ainda, mais à frente, quando comenta sobre o que os regionais diziam sobre suas façanhas, notadamente sobre uma suposta ocasião em que teria se livrado das algemas com as quais os policiais federais o prenderam: "isso é conversa do povo. (...) Quem sabe alguma coisa, não fica dizendo que sabe. E quem sabe muito, sabe que não sabe nada". A conversa encadeia-se e o leitor acaba sendo obrigado a esquecer a poesia ao ficar sabendo, de modo dramático, por que Pedro Biló foi o "herói dos cariús": "Não foi só eu que fiz correria, não. Nós não somos culpados. Os culpados mesmo eram os patrões dos seringais. Nós só cumpríamos ordens. (...) Por que a Funai não persegue os patrões dos seringais, que mandavam fazer as correrias, e só perseguem eu, que sou um pobre coitado, um velho que nem estou enxergando direito? O que eu ganhei com isso? Nada. Da vida só fica mesmo a fama". As violentas correrias, a matança indiscriminada de índios para liberação de suas terras à exploração econômica, são mais conhecidas na literatura como fatos do passado, da virada do século XIX para o XX. Existiram certamente em maior frequência naquele período, mas na entrevista com Pedro Biló revela sua constância e permanência em períodos bem menos recuados, a mando dos patrões e com os interesses de sempre.

A riqueza da reunião dos diversos Papos no livro deve ser reconhecida porque, entre outras coisas, documenta momentos cruciais das populações indígenas e tradicionais acrianas, com efeitos que se espalharam pelo Brasil e, quiçá, mundo afora. Assim, lá estão, entre outros, os impasses em torno da pavimentação da rodovia BR-364 (no trecho que liga Porto Velho a Rio Branco) e o PMACI (Projeto de Proteção do Meio Ambiente e das Comunidades Indígenas), originalmente concebido para minimizar seus impactos (p. 52; 100; 171); a morte do líder seringueiro Chico Mendes (p. 179; 184; 188; 194) e; a partir do alto Juruá, as assembleias indígenas e a formação da Aliança dos Povos da Floresta - um movimento político, de decidido cunho ambientalista, reunindo índios e seringueiros, que contou com o apoio fraterno e poético de Milton Nascimento (p. 223). A propósito, cabe destacar que a Aliança dos Povos da Floresta foi um movimento de efeitos notáveis, que se estende até a contemporaneidade, se considerarmos sua contribuição fundamental para a constituição dos movimentos indígenas no alto Juruá e alhures. Entretanto, pouco se tem registrado ou escrito sobre tal Aliança, que permanece praticamente desconhecida, documentada 
ou discutida nos circuitos acadêmicos. Os Papos que tematizam a Aliança dos Povos da Floresta colaboram assim para minimizar a falta de registros sobre o assunto, em um período tão significativo e tão pleno de transformações no alto Juruá, para não falar do Acre como um todo e da Amazônia. Nesse sentido, vale muito à pena conferir os Papos que se iniciam na página 302, que trazem informações detalhadas sobre o projeto que o BNDES financiou e que permitiu desatar as amarras que ainda insistiam em vincular índios e seringueiros aos patrões e subpatrões seringalistas, seguido de vários Papos entre Terri e Ailton Krenak sobre os rumos da Aliança dos Povos da Floresta.

Uma breve menção aos Yawanawá e aos Poyanawa certamente contribui para realçar os feitos da almejada Aliança naquele período. No que diz respeito aos Yawanawá, no livro estão bem delimitados os desafios que tiveram de ultrapassar. Assim, é que podemos seguir os passos da adesão de uma das lideranças yawanawá aos planos da FUNAI para dar início à exploração madeireira na Terra Indígena do rio Gregório. Um pouco mais tarde, uma segunda liderança da mesma etnia, expõe em outro Papo sua oposição à exploração madeireira e inflama ainda mais o debate acusando a primeira de enriquecimento e distanciamento da vida de seus parentes. (p. 210)

A temperatura do debate aumenta e entra em cena a autoritária, felizmente extinta, Lei de Imprensa, e sucedem alguns direitos de resposta. Terri não se faz de rogado, cumpre os direitos de resposta, mas toma a palavra antes dar início ao Papo: “É muito engraçado um jornalista invocar a lei de imprensa, quando este sempre foi o procedimento da ditadura militar contra os próprios jornalistas... Não precisa utilizar esse expediente intimidatório, pois isso é até anti-ético entre colegas que trabalham na imprensa (mesmo que eu seja um colaborador não-remunerado). $O$ espaço do Papo está aberto para todo tipo de contribuição. É só chegar com a matéria que a gente publica, viu?" (p. 220).

Neste contexto nebuloso é que se encerra a discussão sobre a exploração madeireira nas terras do rio Gregório, dado que a primeira liderança yawanawá antes mencionada reaparece e recua do projeto de exploração madeireira - não sem antes fazer ameaças veladas ao próprio Terri e também lembrar que os Kayapó estariam vivendo um período de prosperidade com a exploração de suas reservas florestais (p. 226) -, clamando por apoio ao desenvolvimento comunitário dos Yawanawá. De qualquer forma, prossegue alfinetando seus opositores ao escrever que é preciso que tais apoios "não se restrinjam a debates, seminários e conferencias e, sim, em propostas reais e viáveis que possam ser implementadas a curto e médio prazos, pois não podemos continuar a viver na miséria, perdendo nossas crianças à custa de uma preservação ecológica e ambiental que veda os desejos de melhoria de nosso nível de vida" (p. 227).

Lendo tantas páginas sobre o plano de exploração madeireira entre os Yawanawá, réplicas e tréplicas, chama a atenção a contribuição fundamental, antes mencionada, dos Papos do Terri: provocar o debate, expor suas próprias ideias e as alheias para qualificar e aprofundar as discussões. $O$ apreço pelo debate às claras, apesar dos destemperos que podem ser encontrados aqui ou ali, certamente é o que confere ao conjunto dos Papos sua marca mais saliente.

Passando aos Poyanawa, um Papo particularmente (p. 274) conta todo o longo e tortuoso percurso que os levou da condição de seringueiros explorados pelo seringalista Mâncio Lima até a auto-demarcação de suas terras, que foi a termo após obterem recursos financeiros em uma viagem que Mário Poyanawa, então sua liderança, fez 
à Inglaterra. Mário viajou acompanhado de Macêdo, à época dirigente do Conselho Nacional dos Seringueiros, da regional do alto Juruá. A Aliança dos Povos da Floresta aparece em relevo e culmina na auto-demarcação das terras poyanawa. Em uma Assembleia Indígena, naquele agitado período, tem-se a notícia que o BNDES havia aprovado a liberação da primeira parcela de um projeto - elaborado por Mauro Almeida, o próprio Terri, Macêdo e Siã Kaxinawá - que contemplava índios e seringueiros, financiando, a fundos perdidos, a safra de borracha dos seringueiros da Reserva Extrativista do alto Juruá e das áreas indígenas do entorno (Ashaninka, Kaxinawá, Yawanawá, Poyanawa, Nuquini e Katukina, entre outras). A obtenção de tais recursos financeiros era certamente uma condição imprescindível para ter continuidade o caminho iniciado, de embate com o regime imposto pelos seringalistas, com a organização das cooperativas, e foi determinante para que se estabelecesse definitivamente sua derrocada no alto Juruá. É no contexto da discussão sobre as conquistas dos Poyanawa, em setembro de 1990, que entra em cena um inflamado discurso do então candidato a governador Jorge Viana (p. 287), conclamando os presentes e o povo acreano a "levantar a cabeça" e se juntar àqueles que "não se vendem por qualquer trocado".

Embora sempre toque em temas candentes, mobilizadores de opiniões divergentes, alguns Papos, em virtude da construção da narrativa, acabam sendo divertidos, dado o tom burlesco. É o que se passa no final do Navegar é preciso quando, na fronteira brasileira-peruana, Terri praticamente encarna uma autoridade, "no maior respeito pela pátria peruana", e impressiona os oficiais do país vizinho com sua "dialética verborrágica" (p. 112-113). No fim das contas, resolve-se a contenda e os oficiais peruanos devolvem mercadorias, espingardas e munições que tinham tomado dos índios no lado brasileiro.

Outros Papos acabam sendo mais tensos. É o que se passa com Conversa para americano cubar (p. 253), no qual Terri apresenta seu diálogo com três americanos em missão do BID (Banco Interamericano de Desenvolvimento), que estavam de passagem por Rio Branco, para conhecer as ações do já mencionado PMACl. Manejando com desenvoltura um conjunto muito maior de informações sobre os impactos da pavimentação da BR-364 (Porto Velho - Rio Branco) e sobre o PMACl do que parecia ser o caso de seus interlocutores, Terri apresenta aos americanos a situação dos Kaxarari, em Rondônia, que tiveram retirado na demarcação de suas terras o sítio da pedreira, em benefício da empreiteira que construía a estrada, a Mendes Junior. Seus interlocutores desconheciam tal quadro e foram realmente "cubados".

O Papo de Índio manteve vivo, por mais de duas décadas, um espaço reservado na imprensa periódica, sempre dedicado ao exercício do debate, feito às turras ou cordialmente, aproximando ou distanciando seus vários interlocutores, diligente, sem deixar os assuntos de interesse das populações indígenas e tradicionais caírem no esquecimento nem serem soterrados pela indiferença, quando não aberta oposição, que contamina a maior parte da imprensa de nosso país até os dias de hoje.

Finalmente, é preciso voltar ao começo para destacar a leitura do prólogo, escrito por Alfredo Wagner B. de Almeida, que, a partir do projeto Nova Cartografia Social, propiciou os meios para viabilizar a publicação do volume. Intitulado A batata amarga dos sonhos: o prólogo dos prólogos, consta nessas primeiras páginas uma extensa reflexão sobre a trajetória acadêmica e pessoal de Terri Aquino. Nele o autor busca situar a contribuição de Terri no 
conjunto da Antropologia, seja nacional ou estrangeira, fazendo sobressair o quanto o ativismo que acompanhou suas reflexões não se desvincula de cânones estabelecidos na disciplina. Muitos não conhecem a biografia de Terri e Alfredo Wagner encarrega-se também de apresentá-la. Não é o caso de reproduzi-la aqui. De todo modo, não deve passar despercebido que foi a partir das pesquisas de Terri Aquino entre os Kaxinawá, enquanto mestrando sob orientação de Júlio César Melatti na UnB, nos anos 1970, que se iniciou o processo que resulta hoje no Acre com $15 \%$ de seu território com terras indígenas demarcadas (p. 12) e sua participação determinante na criação da Comissão Pró-Índio do Acre, CPI-AC (uma das primeiras CPIs e uma das poucas ainda existentes, junto com a de São Paulo). Seguem-se dados biográficos de Terri, algumas palavras sobre suas convicções ayahuasqueiras (que se apresentam também nos próprios Papos que compóem o livro, notadamente no terceiro, em seu diálogo com Carlito Cataiano, ver p. 43) e dissensos com seus opositores, sejam da igreja católica (CIMI, especialmente, mas que, apesar da divergência, tem também espaço para publicar no Papo, ver p. 167) sejam eventualmente algumas lideranças indígenas.

Deve ser aguardada a publicação dos dois próximos volumes com a continuidade dos Papos de Índio, nas décadas seguintes a contar de 1991, na qual o volume apresentado se encerra. Com a publicização dos Papos a um público mais amplo, poderão continuar sendo conhecidas e esquadrinhadas as diversas relações que esse conjunto heterogêneo de agentes entreteceu ao longo do tempo e que certamente complexificou as jogadas no tabuleiro dos movimentos sociais, de populações indígenas e tradicionais, acrianos. Para quem não sabe, aliás, Terri Aquino aprecia jogar xadrez. 